\title{
Erratum
}

\section{Analysis of complications in 430 consecutive pediatric patients treated with intrathecal baclofen therapy: 14-year experience}

\author{
Clinical article
}

To The EdITOR: We appreciate the publication of our paper "Analysis of complications in 430 consecutive pediatric patients treated with intrathecal baclofen therapy: 14-year experience. Clinical article" (J Neurosurg Pediatr 13:301-306, 2014).

After online publication of this article, we realized that the two figures it contained were incorrectly placed and separated from their appropriate figure legends. We are pleased to have the opportunity to correct this error. The corrected figures and appropriate legends are shown below.

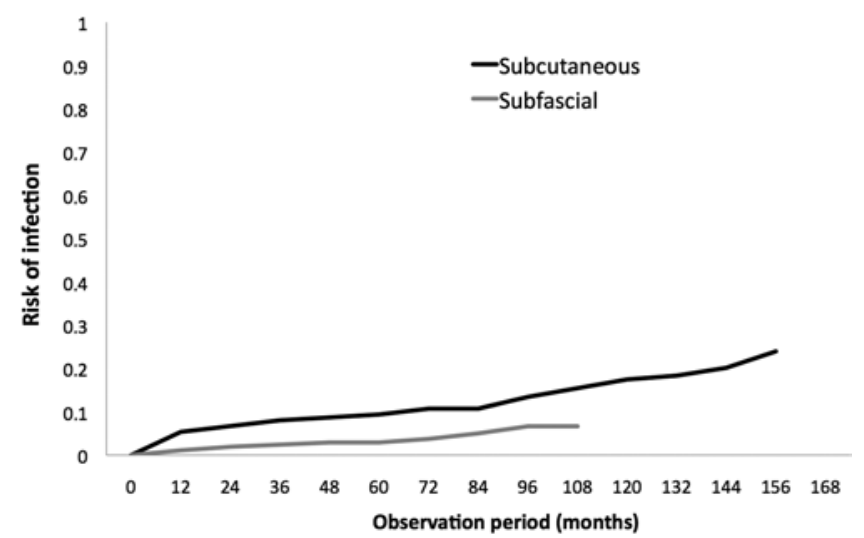

Fig. 1. Kaplan-Meier curve of infections in the subcutaneous and subfascial groups over time.

Please include this information when citing this paper: published online March 7, 2014; DOI: 10.3171/2014.2.PEDS13253a.
We apologize to the editor and readers. The error has been corrected online as of March 7, 2014.

Francesco MotTa, M.D. Clara E. Antonello, P.T. "V. Buzzi” Children's Hospital Milan, Italy

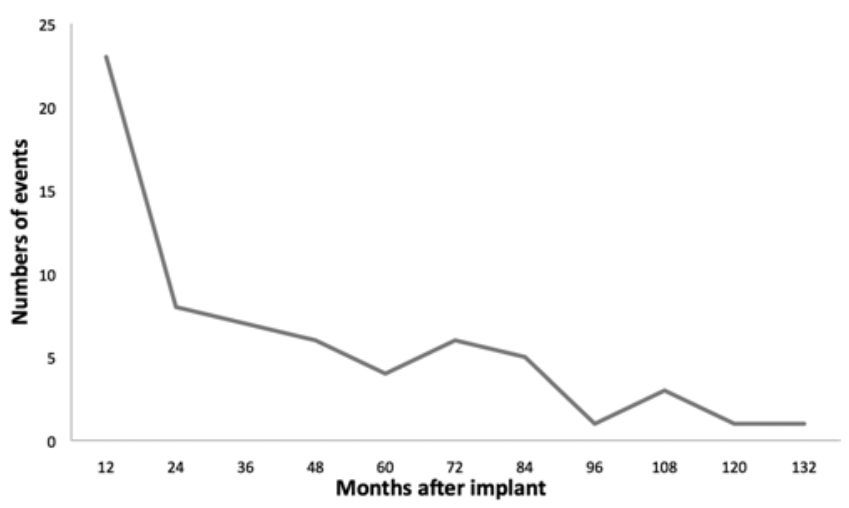

Fig. 2. Graph of adverse events related to the catheter over time. 